carbolic fluid owing to the flies. Thus, in spite of the kidney symptoms, the bleeding was thought to show secondary homorrhage; but the necropsy proved that it was due to a general acute congestion of the whole urinasy tract. There was old ecchymosis in the deep parts of the wound, with one or two bright spots, but no sign of any recent bleeding. The bladder was empty and contracted, its mucous membrane in longitudinal folds, and the ridges bright red from extravasation. The ureters and pelvis were dilated and acutely congested. There were bloody fluid and clots in both ureter and pelvis of the right side, and minute extravasations in the mucous membrane. Those on the left side were empty. The kidneys showed the signs of suppurative nephritis with recent acute congestion, rather more marked on the right side.

CASE 5. Lateral Lithotomy; Extravasation of Urine on ninth eday; Chronic Interstitial Nephratis. - In this case I extracted an oxalic calculus, weighing 156 grains, from a boy aged sixteen years. Though small, it was much branched, and needed a fair-sized opening in the tough prostatic tissue, though it came easily through a small opening in the distensile skin and subcutaneous fat. The temperature kept about normal, and the whole of the urine was coming through the urethra, when, on the morning of the tenth day, we found the penis considerably swollen, and the scrotum and perineum less so. The soft, recent uniting medium in the wound was broken down enough to admit a small drainage-tube into a cavity containing a foul mixture of pus and urine. The penis was relieved by small punctures and slung up to a cradle. This treatment was evidently not enough; and next day there was more swelling and more fever. Though two large firm tubes were introdnced and the whole of the urine drained away through them, there was considerable sup. puration under the skin and in the glans of the penis. When this gradually healed up some weeks after, the tem. perature still kept elevated, at least in the evenings, and the urine was found to be faintly alkaline, with sp. gr. 1005 and 1006. There was a dry tongue and a tendency to diarrhœa, and the patient gradually emaciated. The wound was kept open superficially by a very short wire dilator. Drugs, such as quinine and boracic acid, were given internally. An attempt was made two months after the operation to let the wound close, as much of the urine came through the urethra; but suppuration extended under the skin in to the perineum, and needed a counter-opening. When I left Aden, eightyeight days after the operation, the temperature had only been normal in the evenings for a few days, and some urine was coming through the wound, which was still kept open superficially. The tongue was moist, however, and nourishment was well taken, and recovery seemed near. Extravasation during the healing of a lithotomy wound must be very rare. It seems natural to expect that a considerable obstruction to the passage of urine along the urethra should be a necessary factor in its production. Bat here there was none, and in one of the few cases of extravasation I have seen complicating stricture the stricture was only slight, and admitted a No. 8 catheter at the time. The case stands as a warning against a too limited superficial incision. The subsequent long.con. tinued symptoms of chronic interstitial nephritis probably had some connexion with the fact that on tirst opening up the wound on the tenth day we came on to a small cavity of stinking urine and pus. The temperature before the extravasation took place had been quite normal for several days.

\section{AMPUTATION OF THE PREGNANT UTERUS AT TERM, WITH INTRA-PERITONEAL TREATMENT OF STUMP.}

BY H. M. MILTON, M.R.C.S., \&c., CAIRO HOSPITAL.

IN The LanceT of Nov. 29th, 1890, was published an article in which I reported three successfal cases of supravaginal amputation of the uterus for fibromata, with separate ligature of the vessels and intra-peritoneal treatment of stump. Since that article was written I have performed the same operation once more, also successfully, these four cases being the only ones in which $I$ have practised the operation. On March 8 th of this year an oppor. tunity occurred of applying the same method of operation to a pregnant uterus at term.

A Fellah woman, primipara, aged twenty-three, was admitted at noon, having been in labour about 100 hours She was completely collapsed, but conscious, and her pulse easily felt. Her pelvis was osteomalacic, and the rami of the pubis so approximated that it was with difficulty that three fingers were introduced. The membranes had ruptured three days previously, and the head was jammed on the pelvis. The only possible method of delivery was by an abdominal section, and though the chance of recovery was minimal, she elected to take that chance. At 2 P.M she was chloroformed, and the following operation performed. The $a b$ dominal walls were incised up to two inches above the umbilicus. The uterus was made to protrude, and turned to the right. This brought into view the huge vessels of the left broad ligament stretched on the distended uterus, and a closed artery forceps was easily passed under them, piercing the broad ligament and raising the vessels from the uterus. One handle of the artery forceps was then passed beneath them, and the two handles were held by an assistant ready to be clamped when required. The uterus was then turned to the left and the vessels of the right broad ligament similarly treated. The placenta was readily found at the top of the uterus, and the uterine wall incised below its attachment. The opening in the uterus was enlarged with the fingers, and the child, which had been for a long time dead, was easily removed, the artery forceps holding the vessels of the broad ligament being at the same moment clamped. Some two or three ounces of blood escaped from the uterine cavity. The uterus was then cut across with scissors, a little above the reflection of the peritoneum on to the bladder. No bleeding occurred except as the uterine arteries and veins on either side were cut across, they being at once seized with forceps. The stump of the uterus was washed out with water, draining through the vagina. The vessels of the two broad ligaments, already clamped, were separated one by one and tied with silk, as also were the uterine vessels. The edges of the stump were then sewn together with a continuous catgut sutnre, and the peritoneum united over it with a continuous Lenbert silk suture. The peritoneal cavity was washed clean with sterilised water, a large glass drain inserted, and the abdo. minal wound closed. The whole operation occupied twenty. five minutes. The patient revived for a few hours after the operation, then sank gradually, and died at 7 next morning.

Remcrlis. - In spite of the fatal result, I think operative interference was not only justifiable, but a duty. The operation itself possesses various advantages: it is as easy of execution as an ordinary ovariotomy; there is no possible fear of hæmorrhage at the time of operation except from the slipping of a clamp, and the chance of subsequent bleeding is rendered minimal, as each vessel is ligatured separately. The stump is perfect, being entirely covered with peritoneum, and the peritoneal cavity is entirely closed except for the drainage-tube, which I think might be omitted. As regards the child, its nutrition is in no way interfered with, as the circulation is carried on normally until the moment when the uterus is opened. The preliminary fixing of the clamps round the vessels of the broad ligaments is not absolutely necessary, as generally there is but little bleeding from the torn uterus, but as a matter of caution I think it advisable.

REMARKS ON THE MALARIAL FEVERS OF THE PESHAWUR VALLEY, AND THEIR PROPHYLACTIC TREATMENT.

By Surgeon-Major ANDREW DUNCAN, M.D., \&.

InSPECTOR-GENERAL MunRo has described the Peshawur valley as one surrounded by lofty mountains, with a greab amount of water in it that was stagnating, and an absence of all permanent vegetation. These features, with the constant rotation of annual crops, all tend to produce malarious disease. The types of fever were said to be endemic in the valley, frequently becoming epidemic, remittent, intermittent, congestive remittent, and the ardent or simple continued. The usual rotation of these fevers was said to be as follow:-The simple continued occurred in April, May, and even in June; the remittent and congestive remittent in July, August, and September; 
and the intermittent in October, November, and December. $/$ tion of different races was at once eliminated. The drugs The year 1890 was marked by an uncommon prevalence of that were used as prophylactics consisted of arsenious malarial fever in the Punjab. Taking the week ending acid, cinchona febrifuge, quinetum, and quinine. Fromr October. 11th, Dr. Stephen, the sanitary. commissioner, August lst each man of A Company received once daily showed that for every death from fever that occurred in the three grains of quinine; each man of $B$ Company three corresponding week 1889 , more than three deaths occurred in the week during 1890 . In the districts of Gupinwala, Grijrat, and Sialkot, the recorded mortality per annum reached as high as 269,293 , and 409 per 1000 . The regiment of. which I was the medical officer at the time was stationed in Peshawur. During 1889 it had suffered to an unusual degree from malarial fever when stationed at Thelum, and with this antecedent, and recognising the fact of the unusual prevalence of malarial fever in the P'unjab in 1890 , I thought that a good opportunity of estimating the effects of various prophylactics, and of determining the relative proportion of the different forms of malarial fever that were to be met with, had arisen. My results are set forth in this paper. The 14th Sikhs is composed extensively of Jat Sikhs, so that any disturbing factor due to the predisposi-

grains of cinchona febrifuge; the remaining companies received no drugs. From Aug. 16th $\mathrm{C}$ and $\mathrm{D}$ Companies began to take seven minims of liquor arsenicalis twice daily after meals. From Sept. 15th $\mathrm{C}$ and D Companies took ten minims of liquor arsenicalis twice daily after meals. From Sept. 20th C and D Companies took twelve minims of liquor arsenicalis twice daily after meals. From Oct. 7th $\mathrm{C}$ and $\mathrm{D}$ Companies took fifteen minims of liquor arsenicalis twice daily after meals. From Oct. 11th $\mathrm{E}$ and $\mathrm{F}$ Companies took three grains of quinetum daily. From Oct. 29th A and B Companies took five grains of quinine and cinchona febrifuge once daily respectively, whilst $E, F, G$, and $H$ Companies took five grains of quinetum daily. The following tables show the

TABLE I.

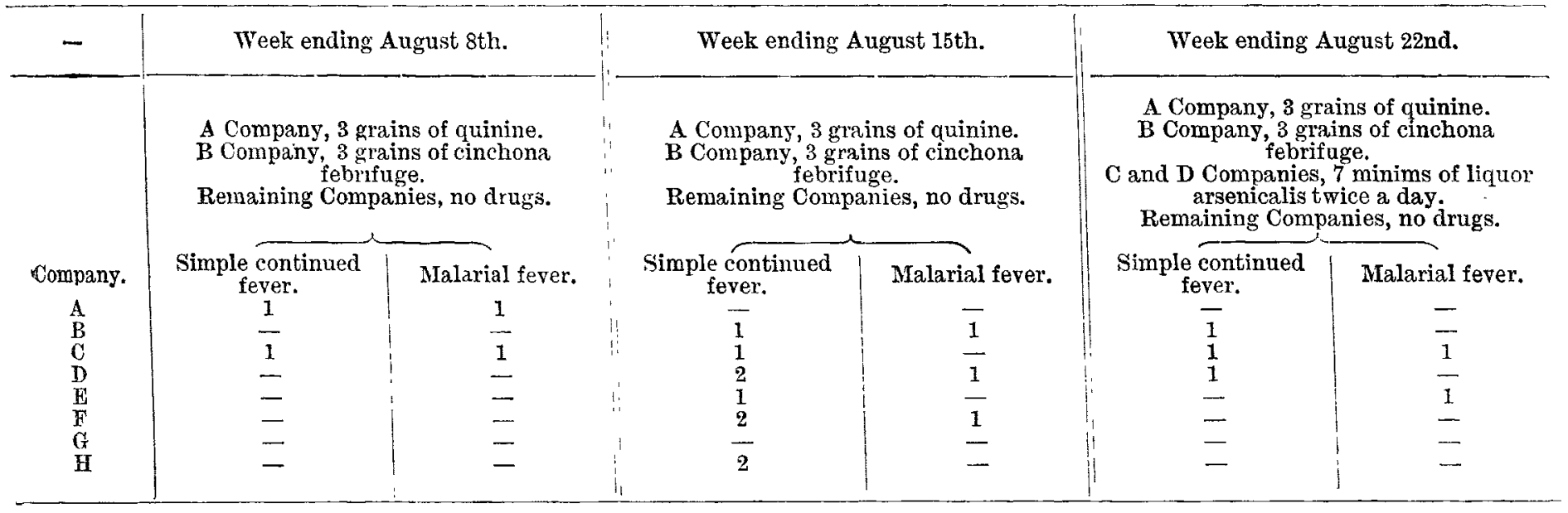

TABLE II.

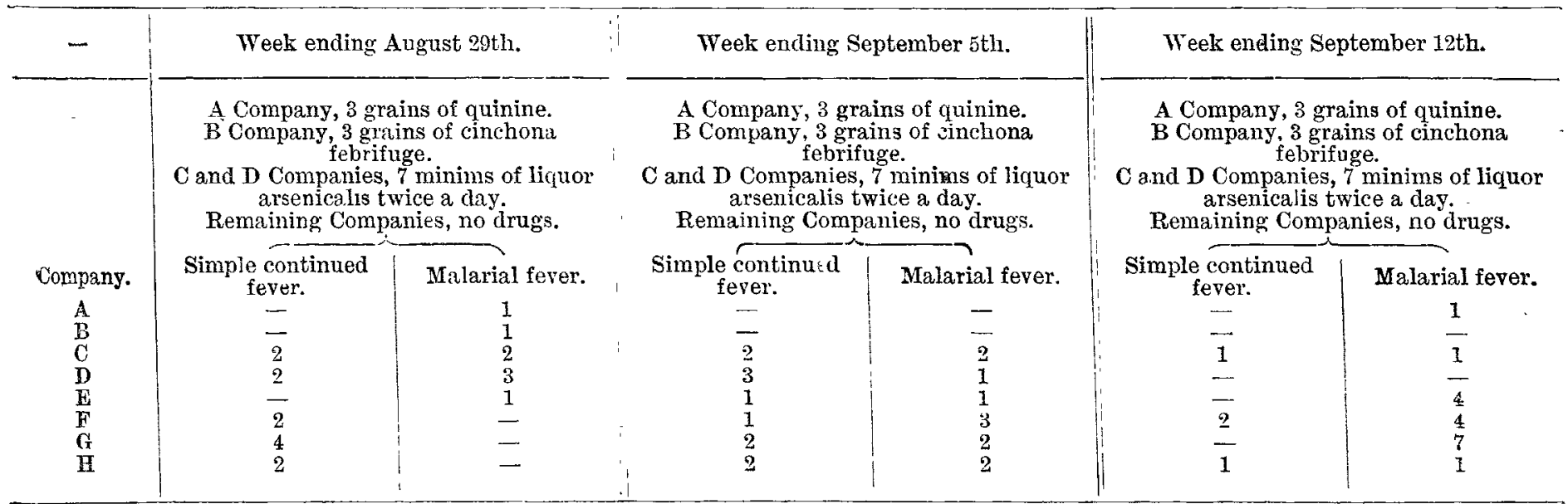

From September 15th C and D Companies took 10 minims of liquor arsenicalis twice a day. From September 20 th $C$ and $D$ Companies took 12 minims of liquor arsenicalis twice a day.

TABLE IIT.

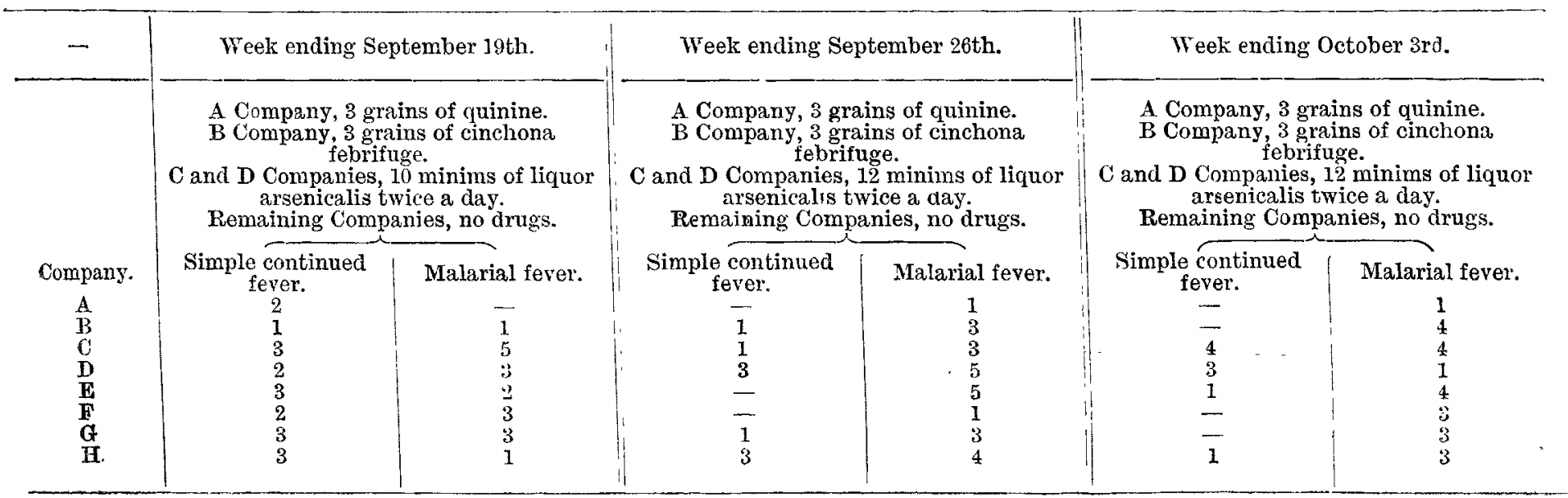

From October 7 th $\mathrm{C}$ and $\mathrm{D}$ Companies took 15 minims of liquor arsenicalis twice a day From October 11th $\mathrm{E}$ and $\mathrm{F}$ Companies took 3 grains of quinetum daily. 
TABLe IV.

\begin{tabular}{|c|c|c|c|c|c|c|}
\hline \multirow[b]{3}{*}{$\begin{array}{l}\text { Company. } \\
\underset{\mathbf{A}}{\mathbf{B}} \\
\mathbf{C} \\
\mathbf{D} \\
\mathbf{E} \\
\mathbf{F} \\
\mathbf{G} \\
\mathbf{H}\end{array}$} & \multicolumn{2}{|c|}{ Week ending October 10th. } & \multicolumn{2}{|c|}{ Week ending October 17 th. } & \multicolumn{2}{|c|}{ Week ending October 24 th. } \\
\hline & \multicolumn{2}{|c|}{$\begin{array}{c}\text { A Company, } 3 \text { grains of quinine. } \\
\text { B Company, } 3 \text { grains of cinchona } \\
\text { febrifuge. } \\
\text { C and D Companies, } 15 \text { minims of liquor } \\
\text { arsenicalis twice a day. } \\
\text { Remaining Companies, no drugs. }\end{array}$} & \multicolumn{2}{|c|}{$\begin{array}{c}\text { A Company, } 3 \text { grains of quinine. } \\
\text { B Company, } 3 \text { grains of cinchona } \\
\text { febrifuge. } \\
\text { C and D Companies, } 15 \text { mioims of liquor } \\
\text { arsenicalis twice a day. } \\
\text { E and F Companies, } 3 \text { grains of quinetum. } \\
\text { G and } H \text { Companies, no drugs. }\end{array}$} & \multicolumn{2}{|c|}{$\begin{array}{c}\text { A Company, } 3 \text { grains of quinine. } \\
\text { B Company, } 3 \text { grains of cinchona } \\
\text { febrifuge. } \\
\text { C and D Companies, } 15 \text { minims of liquor } \\
\text { arsenicalis twice } 2 \text { day. } \\
\text { E and F Companies, } 3 \text { grains of quinetum. } \\
\text { ( } i \text { and } \mathbf{H} \text { Companies, no drugs. }\end{array}$} \\
\hline & $\begin{array}{c}\text { Simple continued } \\
\text { fever. } \\
2 \\
\frac{4}{4} \\
3 \\
2 \\
6 \\
1 \\
-\end{array}$ & 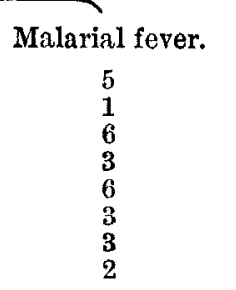 & $\begin{array}{c}\text { Simple continued } \\
\text { fever. } \\
2 \\
2 \\
2 \\
1 \\
1 \\
= \\
-\end{array}$ & $\begin{array}{l}\text { Malarial fever. } \\
\qquad \begin{array}{c}10 \\
12 \\
11 \\
3 \\
8 \\
1 \\
3 \\
5\end{array}\end{array}$ & $\begin{array}{c}\text { Simple continued } \\
\text { fever. } \\
1 \\
\frac{1}{3} \\
\frac{2}{3} \\
1 \\
2 \\
2\end{array}$ & $\begin{array}{c}\text { Malarial fever。 } \\
4 \\
1 \\
7 \\
2 \\
3 \\
3 \\
4 \\
1\end{array}$ \\
\hline
\end{tabular}

From October 29th A Company took 5 grains of quinine once a day.

" " B Company took 5 grains of cinchona febrifuge once a day.

" $\quad$ C and D Companies took 15 minims of liquor arsenicalis twice a day.

The early part of the week as in the week ending October 24 th.

TABLE V.

\begin{tabular}{|c|c|c|}
\hline- & \multicolumn{2}{|c|}{ Week ending October 31st. } \\
\hline & \multicolumn{2}{|c|}{$\begin{array}{l}\text { A Company, } 3 \text { grains, afterwards } 5 \text { grains, of quinine. } \\
\text { B Company, } 3 \text { grains, afterwards } 5 \text { grains, of cinchona } \\
\text { febrifuge. } \\
\text { C and D Companies, } 15 \text { minims of liquor arsenicalis } \\
\text { twice a day. } \\
\text { E and F Companies, } 3 \text { grains, afterwards } 5 \text { grains, of } \\
\text { quinetum. } \\
\text { G and H Companies, no drugs, afterwards } 5 \text { grains of } \\
\text { quinetum. }\end{array}$} \\
\hline $\begin{array}{c}\text { Company. } \\
\mathbf{A} \\
\mathbf{B} \\
\mathbf{C} \\
\mathbf{D} \\
\mathbf{E} \\
\mathbf{F} \\
\mathbf{G} \\
\mathbf{H}\end{array}$ & $\begin{array}{c}\text { Simple continued fever. } \\
\frac{-}{1} \\
= \\
\frac{-}{2} \\
-\end{array}$ & $\begin{array}{c}\text { Malarial fever. } \\
4 \\
3 \\
3 \\
6 \\
12 \\
13 \\
4 \\
1\end{array}$ \\
\hline
\end{tabular}

After this date I was unable to carry on any observation, as I moved to Hoti Murdan to take up the medical charge of my present regiment.

Let us now consider the results gained, as shown by the above tables :-

1. The Nature of the Fever.-From Aug. 1st to Oct. 31st there were 385 cases of fever, of which 261 were malarial and $12 \mathrm{l}$ simple continued. The malarial fevers consisted of Quotidian, 86 cases; tertian, 31 ; quartan, 10 ; irregular, 60 ; remittent, 77 cases.

2. The Relative Preponderance of these varinus Forms in different Months. - They were the following from March lst to October 3lst :-

\begin{tabular}{|c|c|c|c|c|c|c|c|c|c|}
\hline & & & & 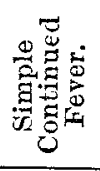 & 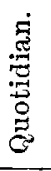 & 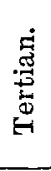 & 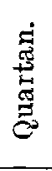 & 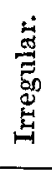 & 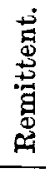 \\
\hline \multicolumn{3}{|c|}{ During month of March } & . & 3 & - & - & - & - & - \\
\hline$"$ & " & April & . & 15 & 3 & - & - & - & 1 \\
\hline "2" & ", & May .. & . & 3 & 1 & 1 & 1 & 一 & 7 \\
\hline \multirow[t]{2}{*}{ " } & 20 & June & .. & 8 & - & 1 & - & - & 1 \\
\hline & & July... & $\cdots$ & 10 & 1 & - & - & - & 6 \\
\hline \multicolumn{3}{|c|}{ From Aug. 1 to Aug. 29} & . & 26 & 4 & 5 & 2 & 2 & 3 \\
\hline \multirow{2}{*}{ ", } & Aug. $30 t$ & Sept. 26 & - & 43 & 22 & 10 & 5 & 21 & 14 \\
\hline & Sept. 27 & Oct. 31 & $\cdots$ & 52 & 60 & 16 & 3 & 37 & 60 \\
\hline
\end{tabular}

It will thus be seen that these results differ somewhat from the cycle laid down by Inspector-General Munro; for the simple continued fevers, instead of ceasing in June, progressively increase to the end of October; the intermittent begin markedly in September; and the remittent are far more marked in October than September. Inasmuch as some authors dispute the very existence of such a fever as the simple continued, it may be well to indicate the form of fever I classify as above. By simple continued fever I mean a fever consisting of a single paroxysm, declining the day after to the normal, generally coming on after exposure to the sun, unaccompanied by any enlargement of the spleen, and not recurring, the patient not being treated with anti-periodics, but taking a single saline mixture. All the cases of fever above tabulated were treated on admission to hospital in this way until the form. of fever became evident. A recent writer on the subject has expressed the opinion that simple continued fever does not exiso in India, but that fevers in India resolve them. selves into malarial and enteric. I, however, fail to see how a fever, consisting of a single paroxysm and with the features above described, can be considered malarial; as regards enteric, they can hardly, I suppose, be relegated even to the class of abortive enteric fever even in India, where enteric fever is supposed to arise from climate, and where its returns have recently so increased. With regard to the increase of enteric fever, however, the report of the late Commission may be read with advantage.

3. The Fffect of the Anti-pcriodics employed.-These were arsenious acid, auinine, cinchona febrifuge, and quinetum. Arsenions Acid. - This was strongly recommended by Tommasi-Crudeli in Italy in 1881 . In 1882 Dr. Ricchi, Chief of the Medical Staff in charge of the Roman and South Italian railways, when malarial fevers were urgent gave it to 455 workmen. Of these, 338 were either cured of fevers which they had, or prevented from contracting them. In 1883 these experiments were continued on 78 individuals in the Borino district, of whom one-half took arsenious acid. At the end of the fever season the men who had taken the drug were nearly immune, 36 out of the 39 had had no fever, the remaining 3 having had only slight attacks, whilst 39 who had not taken it had suffered from fever, many of them severely. My experience with this drug has, however, not confirmed these results. I tried it in 1886 and in 1887 without any benefit; and in 1890 the results were as follows:-C Company, from Aug. 16th to Oct. 10th, taking liquor arsenicalis (seven minims three times a day increased up to fifteen minims three times a day), had 18 cases of febricula and 24 cases of malarial fever; whilst $D$ Company, under similar circumstances, had 17 cases of febricula and 16 cases of malarial fever. Compared with E, F, G, and H Companies, who took no prophylactics, the results are as follows:-

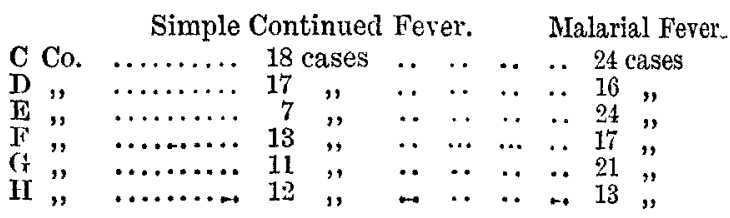

I take the period up to Oct. 10th only, as during this time $\mathrm{E}, \mathrm{F}, \mathrm{G}$, and $\mathrm{H}$ Companies received no prophylactics. Thus the arsenious acid exerted no prophylactic effect; if anything, the companies not taking it were rather freer from malarial fever than those taking it, whilst with regard to 
simple continued fever the former decidedly enjoyed the advantage.

Quinine and Cinchona Febrifuge. - From Aug. 2nd to Det. 31st, A and B Companies took respectively three grains, increased in the last week to five grains, of quinine and cinchona febrifuge respectively. I will first give the results up to the week ending October 10th, and compare them with the companies taking arsenious acid, and with the companies not taking any drugg. The results are as follows :-

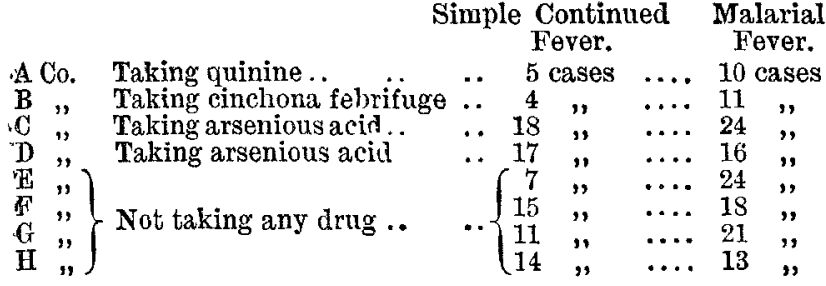

Here we see that the quinine and cinchona febrifuge exerted a decided prophylactic effect. But after the week ending Oct. 10th the drugs seemed to lose their effects somewhat; indeed, in the week ending Oct. 17 th there were more cases of malarial fever admitted in each of these companies than in the others.

Quinetum.-E and F Companies began to take three grains daily from Oct. 11th; from Oct. 18th $G$ and $H$ Companies also took the same dose. The results up to 0ct. 31st in these companies, as compared with the other companies, were as follows. From Oct. 11th to Oct. 31st:-

\begin{tabular}{|c|c|c|c|c|c|c|}
\hline & & \multicolumn{3}{|c|}{$\begin{array}{c}\text { Simple Continued } \\
\text { Fever. }\end{array}$} & \multicolumn{2}{|c|}{$\begin{array}{c}\text { Malarial } \\
\text { Fever. }\end{array}$} \\
\hline $\mathrm{Co}$ & Taki & & ases & & & ases \\
\hline & febrifuge & 3 & $"$ & $\cdots$ & 16 & \\
\hline & cill.. & & "y & $\cdots$ & $\begin{array}{l}2 \\
11\end{array}$ & ", \\
\hline & & & $"$ & $\cdots$ & 23 & $"$ \\
\hline & $\mathrm{Ta}$ & & " & $\cdots$ & & ", \\
\hline & & & $"$ & $\ldots$ & & \\
\hline
\end{tabular}

The period is too short to draw any valid conclusions.

General results. - Sir Anthony Home, when principal medical officer of the Ashanti Expedition, came to the conslusion that quinine exerted no effect as a prophylactic against malaria. The French in Algeria have also found no good effects. But the contrary opinion has been formed on many occasions. Van Buren and Hammond in America have found it to protect men from malaria. At Peshawur in 1866, it was found that the men not taking it had an admission.rate for malarial fever nearly threefold that of those who took it; and my tables quoted above show that both quinine and cinchona febrifuge do exert a prophylactic effect. Arsenious acid, on the other hand, has not fulfilled the expectation formed from the results of the experiments in Italy. The strength of the various companies during the dates specified was practically the same.

\section{A THEORY OF SEX.}

BY ANDREW WILSON, F.R.S.E., F.L.S., \&e, LATE LECTURER ON ZOOLOEY AND COMPARATIVE ANATOMY, EDINBURGI MEDICAI SCHOOL, ETC.

SOME years ago I placed on record in the pages of the medical journals a short statement regarding a theory of sex which it seems advisable to recapitulate at greater length, if only by way of affording opportunity for the discussion of this interesting and fascinating topic. Regarding a theory as a guide to the elucidation of truth, and considering a correct theory as one which explains all the facts and is contrary to none, I submit my views for criticism on this rational basis. It may be proved that I have erred in my conclusions through the deficiencies of my premisses, and that mynotinns of sex evolution are untenable altogether ; but at the most and best I submit my views as constituting a provisional and tentative hypothesis only, and as one which subsequent research will either confirm or altogether refute. Beginning thus with a free hand, let me briefly state the gist of the theory in question. It is a tolerably safe maxim in biology, and in other departments of science as well, that we should not ascend into the clouds for explanations of things which lie at our feet. Sex should be, and is, no more mysterious as to its origin than, say, the nature of liver-functions or of pancreatic duties. It only presents greater difficulties, perchance, in the way of solution, and is environed by more complex conditions than is the question of hepatic work. Yet, to discover the conditions to which the cansation of sex is due, we may not go far astray if we search among the common functions and actions through which life at large is maintained and conserved. Amid such functions that of nutrition stands out in bold relief as one which exercises a very prominent influence on the development of living tissues. Sir James Paget long ago pointed out how nutrition affects development, and Herbert Spencer has emphasised this teaching in many ways in his biological discussions. In so far as the origin and determination of sex are concerned, it is therefore a perfectly just observation that nutrition is likely to play a very important part in its evolution. This primary consideration is important, because, if it may be suggested with a fair show of reason that nutrition lies at the root of sexual differentiation, we may claim to have at least paved the way for the further and scientific consideration of the whole subject.

Wellnigh every recent theory of sex which has had a basis of scientific nature, as distinguished from theories which are merely the outcome of isolated and detached ideas regard. ing sexual differentiation, has started from the stand point of nutrition as the one factor of import in sex production. As an illustration of a recent theory of sex, that elaborated and illustrated by Messrs. Geddes and Thomson in their "Evolution of Sex" may be mentioned. These authors hold that a latabolic habit of body (or conditions in which there is a tendency to the predominance of waste over repair) favours the production of males. The opposite habit, that of anabolism, which favours constructive processes, on the other hand, tends to the production of females. Here it is evident nutrition is regarded as the starting-point of everything. It is the general factor which acts upon the special phases of sexual development. Experimental evidence is called to aid the induction thus made. High-fed tadpoles turned out males in gross excess, while "left to themselves the percentage of females was rather in the majority." How far the case of tadpoles can be regarded as applying to the mamnialia is, of course, a serious consideration with the critic of these facts. We must not forget that while the adult female is almost always the stronger and the best developed in lower life, the case is reversed among mammals. This alone is a biological fact worth bearing in mind ; for if the male be the stronger in the human species, as he undoubtedly is, it seems illogical to conclude that the laws of sex-differentiation in lower life, with its bigger females, should apply to higher existence.

What help we obtain from embryology is naturally of great importance in the matter before us. Everyone knows that the male and fema'e generative organs are developed, each out of a common or indifferent type, just as their adult homologies are plainly enough indicated. About the sixth week of intra-uterine life the genital glands begin to appear. The male organs are formed by specialised developments of the common type, just as the female organs appear in their turn through equally specialised developnents of the same type. If the development of an animal shows us the history of its race-evolution-that is, if embryology be a guide to ontogeny, - then it seems clearly enough demonstrated that the sexes of higher animals have arisen out of a once common or hermaphroditic type. To put the matter plainly, it would seem as though each foetus at its ontset hangs or rests in equilibrium as regards its sex. Something occurs in its history which gives it a bias to the male or to the female side, and it is precisely the nature of that something which it is the business of exact science to determine, and of theory to provisionally indicate.

Like my predecessors in the domain of theoretical expla. nation, my faith is large in the influence of nutrition as the factor which determines sex. That subsidiary causes, heredity, temperament, and other influences may also operate to this end, I am far from denying; but to nutrition, even from the period of the ovum and its fertilisation, I attribute the main cause of sex-differentiation. I take for granted that menstruation is really ovulation, and that the latter process consists in the development and extrusion of ova which are fertilised, in man, nsually in the Fallopian tube. Now, prior to fertilisation there can, of course, be no question of sex. Fertilisation alone determines the begin. ning of embryonic development, and shortly stated, my theory of sex therefore holds, that when an ovum is ferti- 